\title{
Partnership Funding in flood risk management: multi-level stakeholder engagement - a question of roles and power
}

\author{
Thomas Thaler ${ }^{1, a}$, and Sally Priest ${ }^{2}$ \\ ${ }^{1}$ Institute of Mountain Risk Engineering, University of Natural Resources and Life Sciences, 1190 Vienna, Austria \\ ${ }^{2}$ Flood Hazard Research Centre, Middlesex University, NW4 4BT London, United Kingdom
}

\begin{abstract}
The paper examines the new flood risk policy discussion in England and Wales. The summer floods in England in 2007 caused large damages to the environment, economy and humanity. Following this key flood event, the Government has started to redefine the national flood and coastal risk management policy in England and Wales. The key issue in the new policy agenda is to encourage the responsibilities of local authorities and reduce the central role of flood risk management. This decentralisation in flood risk management has a series of consequences in the development of new governance structures. The main reason for this shift from central to local level is the belief that local authorities deal with public administration tasks in a more efficient way. Nevertheless, the main problem is the gap between the delegated tasks and the lack of transfer of resources, especially the issue concerning funding is still unclear and unresolved. This constraint will go with fiscal and administration cuts. The consequences will be (1) 'hollowing out' of the Government with the downscaling of the responsibility towards local actors and (2) without proportional transfer of resources to local authorities they will not be able to deal with new tasks. Therefore, in practice there are many limitations, barriers and concerns with the new policy direction.
\end{abstract}

\section{Introduction}

In recent years, the localism-debate has become more popular in policy discussion $[1,2]$. The outcome has been a re-arrangement of roles and responsibilities of the state and individual households. Key drivers for this new policy include (1) the European Union, with regional and local policies and programmes, such as the Rural Development Program (CAP), Urban I and II as well as various directives (Water Framework Directive or EU Floods Directive), (2) national programmes, such as regional and local knowledge clusters or re-urbanisation programmes, (3) request for more political participation, accountability, and legitimacy by local groups and (4) recent financial and economic crises $[3,4,5,6]$. The central government used the new discussion to reorganise the role, responsibility and function of the public administration, especially with the introduction of nonstate actors in policy discussions [3, 7]. The main characteristic of new localism debates is focused on encouraging local public authorities to increase their role and responsibility in the flood risk management policy process. This includes a shift of responsibility and duties between national and local bodies, but often without a change of legal framework or shift of additional resources and power between different scales [7] resulting in a new understanding and definition of the state construction [8, 9]. Yet 'new localism' debates focus on key principles of economic effectiveness, accountability and legitimacy
[10]. For Boyle [11] the localism debate has been more than only a decentralisation of responsibility towards lower public authorities and organisations. Localism processes allow the public administration an increased democratic legitimacy and accountability of their policy actions [12]. On the other hand, scholars see in the localism process as a dangerous development of change in the state structure with a negative impact on democratic structures and social equity $[3,13,14]$. A key issue in this new policy agenda is to encourage the responsibilities of local authorities and reduce the central organisation of flood risk management. In this line, the flood risk management policy follows other policies.

The aim of this paper is to present the impacts of the reorganisation on the flood risk management policy in England. We focussed our research towards the introduction of the Partnership Funding scheme and its consequences.

\section{Methodology}

This paper seeks to investigate the re-organisations in English flood risk management policy, based on the introduction of the Partnership Funding. To identify and evaluate the new funding regime this paper uses a qualitative and explorative research design. A semistructure qualitative approach was adopted to understand the impact, the challenges and the barriers in the policy discussion. This research interviewed a range of key

\footnotetext{
${ }^{\mathrm{a}}$ Corresponding author: thomas.thaler@boku.ac.at
} 
stakeholders $(n=15)$ - included professional in the areas of Cumbria and Northumberland, public authorities, academics working the area of flood risk management and other stakeholders at risk of flooding.

\section{Study sites description}

The research is based in two study sites in Cockermouth and Morpeth. The selection of the two case studies is based on various criteria (matching) with the aim of hypothesis generating. Key selection criteria were the implementation of the new funding regime in flood risk management. A second argument was the previous flood frequency and recent flood history, especially key flood events.

\subsection{Cockermouth}

The civil parish of Cockermouth is located in the highly frequented tourism area in Lake District in the Borough of Allerdale, with the two rivers the Cocker and Derwent confluence close to the town centre. Cockermouth was flooded three times in less than four years - in 2005, 2008, 2009 and in 2016. The 2009 event affected the whole of Cumbria as well as parts of Ireland and Scotland, but the Derwent and Cocker valley were particularly hit in 2009 (interviewee_7; interviewee_8). Flooding occurred due to the high peak flow from the River Derwent (see Figure 1). In Cockermouth more than 693 residential and 225 businesses were affected [15]. Cockermouth includes a large number of rural oriented small-medium businesses, with more than $80 \%$ of them affected by the flooding (interviewee_7; interviewee_8).

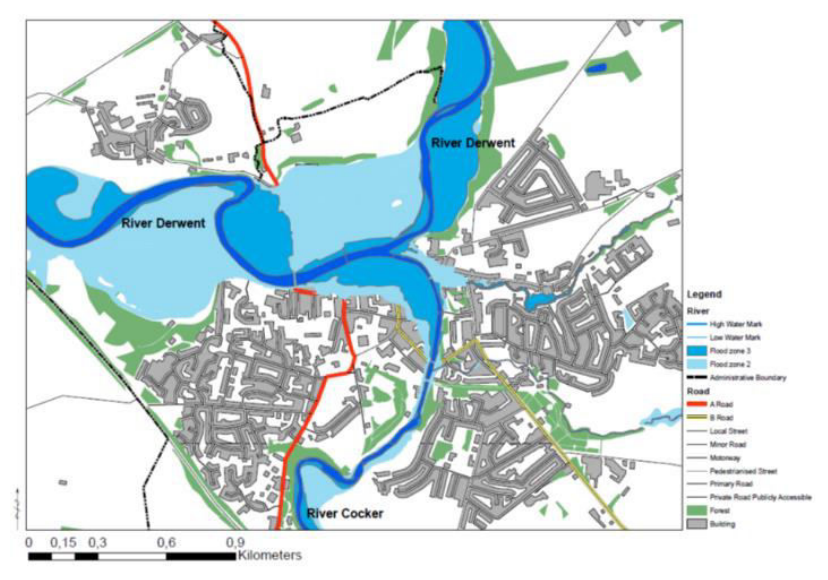

Figure 1. Overview Cockermouth

Source: own development; (C) [16]

\subsection{Morpeth}

The second case study area Morpeth is the administrative head of the Northumberland County Council. The county town has had a long flooding history at various levels: e.g. in 1963, 1967 and 2008. Key problems in the town are fluvial flood hazards from the River Wansbeck as well as three smaller rapid response catchments (Cotting Burn, Church Burn and Postern Burn) which run through the town (interviewee_14). Furthermore, Morpeth is affected by problematic surface runoff (interviewee_15). After the 1963 flood event, the public administration implemented flood defence schemes, mainly by improving and providing new river defences in the town, but for only some areas (interviewee_15). High Stanners and Mitford Road (see figure 2), for example, had no flood defence scheme. The rest of the town had a flood defence scheme of about 1:50 year standard of protection, with the exception of the Middle Green area, which had a higher defence standard - around 1:75 year flood defence. The heights of flood defence scheme were based on the flood depth from the 1963 flood event (interviewee_10). In 6th and 7th of September 2008, around 964 properties (e.g. 403 privately owned and 212 socially rented properties) were affected by the flood event [17].

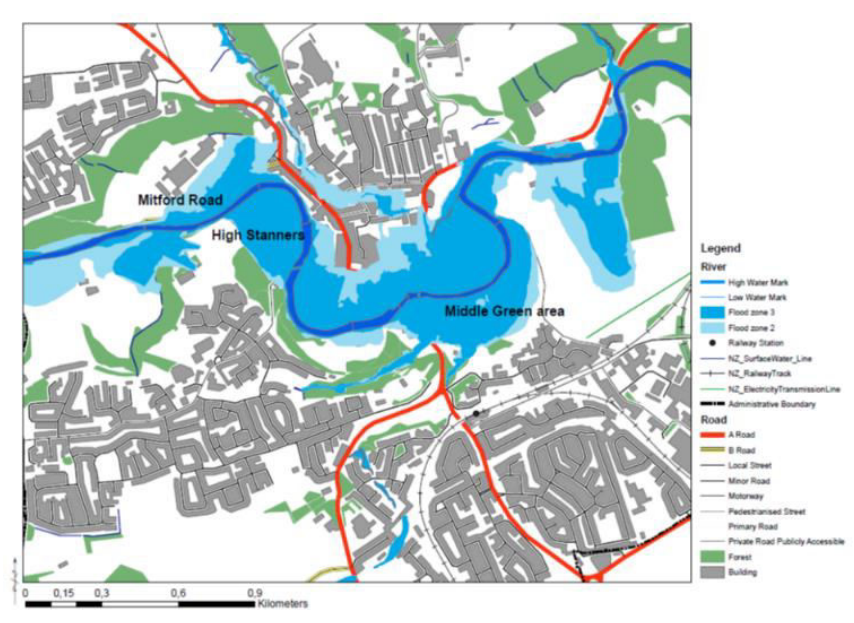

Figure 2. Overview Morpeth

Source: own development; (C) [16]

\section{Results and discussion}

\subsection{Partnership Funding policy in English flood risk management system}

The introduction of the Partnership Funding scheme occurred in April 2011. There were multiple drivers for change and a move back towards locally-based flood risk management. Key factors included the results from the EA study Investing for the Future published in 2009 [18] and the recommendations from the Pitt Review [19]. The former study recognised the need for an increase to the annual flood risk management budget of around $£ 20$ million, exclusive of the annual rate of inflation [18]. However, based on the Government spending review 
(October 2010) and with the result of the current pressure on public spending and resources, the central Government reduced the public national funding in the next years. The spending review foresaw a reduction of the capital works from $£ 354$ million (2010-11) to $£ 259$ million (constant over the next spending review period) as well as the revenue funding (maintained work, emergency response, hazard and risk mapping and modelling) from $£ 275$ million (2010-11) to $£ 226$ million (2014-15). One reason for this budget reduction is the fiscal squeeze and state budget deficit. However, the Government announced an increase of an additional $£ 120$ million for new flood defence buildings in the next two years, with a key objective of economic growth [20].

The UK central Government has recognised the need for additional financial contributions from third parties (i.e. non-state actors, EU or county councils). This allows the possibility to realise more flood alleviation schemes, and in particular if they do not realise the necessary requirements of the $100 \%$ funding. In terms of contributions, the Partnership Funding scheme is based on external contributions, if the results from Partnership Funding calculator suggest that the full national grant cannot be met. Despite this, there are no real substantial differences between the previous funding regime and Partnership Funding. In addition, formal approval has been re-designed under the new system. In a Partnership Funding scheme, the risk management authorities (such as the EA, a LLFA, a district council, an IDB), a water company or a highway authority) have to develop and coordinate all requested paperwork for the new flood defence scheme. A new role of the EA is to monitor and steer the local authorities planning process. Furthermore, the Partnership Funding scheme includes additional administration steps in the overall process; in particular to guarantee (legally) the financial contributions from each of the actors (national and third parties). However, discussion of a change in the national flood risk management funding regime to open it to third actors is nothing new. In the past years, owing to lack of national funding, the EA tried to encourage private and local actors to contribute to the flood defence schemes, but with low success (interviewee_9). Nevertheless, the success of the new funding scheme is debatable and raises the question of whether the contribution by third actors can close the funding gap from current austerity policies.

\subsection{Political mobilisation at local level}

The introduction of the Partnership Funding, encouraged a change in the governance structure as well as their interaction. Today, the English flood policy discussion includes more and different actors who are involved in the decision-process. The local stakeholders in Cockermouth and Morpeth show a genuine interest, knowledge and resources in the development of a flood defence scheme in the town. In general, Morpeth and Cockermouth have atypical social classes as compared to other areas of England within both communities showing low levels of social deprivation in their administration unit. In both case studies, the key actor group has been identified as the local Flood Action Group (FAG), which has been organised by local private households as a selfhelp group. The creation of the FAG is strongly based on the interest and frustration of local residents after recent flood events. Results from the interviews highlighted that the first role of the FAG was to create a voice through which to lobby for a local flood defence scheme to protect their properties. Consequently, in this way they have taken over this lobbying role from local politicians.

In Morpeth, for example, the members of the local FAG are generally well educated (e.g. lawyers, or architects) and they have a good knowledge about the flood risk problem. Moreover, they have a good network to the various local political actors in the ongoing flood risk policy discussion as well as being able to argue and lobby in an effective way (interviewee_10). They show a profound knowledge about the topic as well as social and cultural capital and the right habitus [21]. They recognised the influence and potential power they have and have understood the need to get involved in the decision-process in order to realise the defence scheme. In sum, the network towards Members of Parliament and County Council played an important role in the case studies. Above all, the members from the EA have to communicate to the local stakeholders and to take their views into account.

\subsection{Incentives for local contributors}

The co-operation between the EA and local actors' often was initiated after recent flood events or a series of different flood events (i.e. Cockermouth). In the case study of Cockermouth, the partnership approach between the community and the EA began mainly as a result of the 2009 floods. Between the years 2005 and 2008, Cockermouth was affected partly by two small flood events. After the 2005 floods, some residents of the town organised for their area a first local self-help group. However, the organisation had no wider diffusion to the whole town. The 2008 flood event re-enforced the creation of a second local self-help group in Cockermouth, to tackle the surface runoff problem in the Gote Road. The Gote Road organisation started an intensive relationship with local and national politicians as well as with the regional office from the EA (interviewee_8). The 2009 flood caused a large impact on the whole town with the creation of the Cockermouth FAG. Furthermore, the role of the Cockermouth FAG shifted from a lobby group to a professional partner in the discussion. The already existing experiences from the previous flood events as well as through broader interaction in the community, recently the FAG could attract new members with different backgrounds and knowledge (interviewee_2). The FAG collaborated with an external consultant company to present their first flood risk management plan for the town on a professional 
basis. At the beginning, the EA was reported to be mainly reserved and defensive regarding co-operation with FAG (interviewee_8). However due to the increase in professionalism of the local FAG, the EA opened the door to the FAG to be part of the planning process; this was a shift from a top-down relationship to a more equal partnership between the different actors. In summary, a key aspect was the change in the local FAG by incorporating internal and external knowledge, such as recruitment of specialists and collaboration with private consultant groups (interviewee_8; interviewee_9: interviewee_10). The FAG was able to increase their scope of action and the relationship with local and Members of Parliament (scale jumping). Analysing the interviews, the jumping scale mobilised local actors to interact at a higher level (regional and national level). Here, the local actors moved to a higher level to ensure their interests. Furthermore, interviewees reported a slight opening of the EA towards local stakeholders in the past years. The shift has been partly away from a strong topdown approach with a low influence and power of stakeholder participation (mainly consultant approach) towards a broader co-operative process in the decisionmaking. Today, the EA negotiate with the different actors more intensively and they also take the local views, ideas and concerns into consideration. At the same time, the local actors have to take part in the discussion process. The co-management approach between the national and the local actors moved from a consultative towards more a co-operation approach $[22,23]$. Thus, the local actors have become more responsible and active in the flood risk management discussion, especially in the design of the new defence scheme. However, responsibility and ownership remains in the hand of the EA, because they own the defence scheme and they are responsible for the maintenance.

\subsection{Conflicts and barriers}

The Partnership Funding scheme includes various problems, challenges and barriers in the implementation of the policy. First, there is the question of fair sharing of responsibility between the different actors. The Partnership Funding scheme only includes flood defence schemes where the EA is responsible for the scheme. Since the introduction of the new Flood and Water Management Act [24] the local actors (LLFA) are responsible for the management of surface runoff. In the case of Morpeth, fluvial and pluvial flooding are the main flooding problems. Within the new Act, the Northumberland County Council as LLFA is responsible to manage the problems with surface runoff and risk from ordinary watercourses. This causes conflicts and misgivings between both actors, because LLFA expect financial contributions from the EA. Second, there is the question of fair risk-sharing [25]. The Partnership Funding scheme foresees a fixed amount from the national funding sources. In the past, the EA matched any additional costs. Nowadays, the EA has shifted some of the financial risk towards the third actors. Consequently, the third actors have to increase their contribution if the project costs increase. A third point relates to the financial contributions. However, the local actors were not able to close the financial gap. The shortfall of $£ 700,000$ was in the end paid by Cumbria County Council (interviewee_9). In contrast to the Morpeth case study, no private actors were integrated in the funding scheme at all. The Northumberland County Council did not ask for any other actors to contribute to the scheme. This was mainly based on a political decision by the County Council (interviewee_15). Here, the local FAG has been shown as a strong lobbying and pressure group. Addressing the financial contribution by the Northumberland County Council it has shown a strong interplay between the local actors and the Members of Parliament. The result of this political decision was that other projects in local authorities across the county cannot longer be completely funded by Northumberland County Council. The County Council have to request additional contribution from third actors (interviewee_15). This includes that Partnership Funding encourage a shift in the flood risk management away from a public good towards a club or event private good [26]. In particular, areas which require funding from third parties need well-established social and cultural networks to realise their flood defence scheme. Furthermore, decision processes of the selection of flood defence schemes is more based on the political will, relationships and interests; rather than an objective decision process. Spaces of engagement (networks) have a more important role at local level [27]. We identified that the national Government has no clear guidelines on how to implement Partnership Funding in practices. Currently, the implementation process is strongly based on local actors and their interests as well as the EA (interviewee_9; interviewee_10). Furthermore, analysing the interviews results indicate deficiency in the knowledge transfer between national and local authorities. Also, a clear problem is the aspect of democratic process (legitimacy) in flood risk management, especially with the non-elected local FAG and the EA. This has resulted in the decision process tacking a backwards step in the selection of the flood defence schemes away from depoliticisedtechnocratic decision-process practices (introduced under the priority scoring scheme) to a charity hazard decisionprocess practices. This results in an uneven development in the country, owing to the unequal capacities at the local level [28, 29]. A key problem is the question of power sharing between the national and local actors, especially in the planning process. The interviews show that the willingness to enable local actors to contribute to the planning process depends strongly on the involved people with the result that the local actors have the responsibility to financially contribute.

\section{Conclusion}

Due to the recent developments the role of the state and individual responsibilities for flood risk management are now under review [30]. The new policy agenda implies a change in the relationship between the different actors [31]. The results show an increase in the number of actors 
in the ongoing policy discussion (equalling a new governance framework). Secondly, the new localism and Partnership Funding policy empowers local actors. Thirdly, the local actors are more involved in the decision-making process. Nevertheless, we have shown that the outcomes strongly depend on local capacity to use these opportunities. We have identified that especially the middle class professionals with expertise and skills (e.g. planners or lawyers) have gained from the new policy direction. A key point for the successful capacity building at local level is the membership of the local actors, especially the FAG. The FAG plays a crucial role in the overall discussion, especially in the bargaining process with the EA. Here, private households replace the local political representatives. Furthermore, the Partnership Funding has encouraged a new organisational culture, skills, knowledge and competences [32]. The remaining question is whether the new localism in flood risk management is more than only a decentralisation of responsibility. Overall, Partnership Funding encourages local actors to get involved in the decision-making process. This includes a new space creation for local actors, which includes a shifting of power towards nonstate actors [33]: in our case towards the FAG. Subsequently, Partnership Funding and new localism policy foresees the promotion of wealthy-rural areas, where local actors want and have the experience and capacity to wield it. Nevertheless, this study shows that the 'successful' implementation of Partnership Funding refers to the questions of local capacity and legitimacy of the involved actors, especially in refer to the FAG [34, 35]. Communities who fail to achieve these criteria will lose out from this new policy [36].

New actors, especially the local FAGs, closed the political vacuum to ensure and to satisfy their needs and interests. Subsequently, the network as well as the knowledge and the habitus have become a central factor in the policy process. The consequences were that within the introduction of the Partnership Funding scheme led to a shift in the state spatial process [3], away from a singleequal spatial strategy towards a multiple - individualised approach, where capability of local actors can secure their interests and needs. Subsequently, the Partnership Funding scheme enforces the uneven development between local authorities. We conclude that Partnership Funding follows the language of Big Society debate introduced by the Conservative Party, where private stakeholders take over state tasks. Nevertheless, the rhetoric is not matched by reality, because the National Flood and Coastal Erosion Risk Management Grand in Aid (FDGiA) provide approximately $93 \%$ of the flood defence budget [20].

\section{References}

1. Neal S. (2013). Transition culture: Politics, localities and ruralities. Journal of Rural Studies, 32, 60-69

2. Clarke N. and Cochrane A. (2013). Geographies and politics of localism: The localism of the United
Kingdom's coalition government. Political Geography, 34, 10-23

3. Brenner N. 2004 New State Spaces. Urban Governance and the Rescaling of Statehood Oxford Univ. Press, Oxford

4. Benson D. and Jordan A. (2010). The Scaling of Water Governance Tasks: A Comparative Federal Analysis of the European Union and Australia Environmental Management, 46, 7-16

5. Cohen A. (2012). Rescaling environmental governance: watersheds as boundary objects at the intersection of science, neoliberalism, and participation. Environment and Planning, A 44, 2207-2224

6. Cox K. R. (2013). Territory, Scale, and Why Capitalism Matters. Territory, Politics, Governance, 1, 46-61

7. Coaffee J. and Johnston L. (2005). The management of local government modernisation. Area decentralisation and pragmatic localism. The International Journal of Public Sector Management, 18, 164-177

8. Brenner N. and Theodore N. (2002). Preface: From the "New Localism" to the Spaces of Neoliberalism. Antipode, 34, 341-347

9. Rosol M. (2011). Community Volunteering as Neoliberal Strategy? Green Space Production in Berlin. Antipode, 44, 239-257

10. Coaffee J. (2005). New localism and the management of regeneration. The International Journal of Public Sector Management, 18, 108-113

11. Boyle D. (2009). Localism Unravelling the Supplicant State New Economics Foundation, London

12. Gualini E. (2006). The Rescaling of Governance in Europe: New Spatial and Institutional Rationales. European Planning Studies, 14, 882-904

13. Wissen M. (2009). Contested terrains: Politics of scale, the national state and struggles for the control over nature. Review of International Political Economy, 16, 883-906

14. Featherstone D., Ince A., MacKinnon D., Strauss K. and Cumbers A. (2012). Progressive localism and the construction of political alternatives. Transactions of the Institute of British Geographers, 37, 177-182

15. Cumbria Resilience (2011). Cumbria Floods November 2009. Learning from experience recovery phase debrief report. Cumbria Resilience Forum, Carlisle

16. Edina (2012). Edina Digimaps Ordinance Survey Service. University of Edinburgh, Edinburgh

17. JBA (2011). Castle Morpeth Borough Council. Flooding in Castle Morpeth 6 and 7 September 2008. Independent Review, Pitsford

18. EA (2009). Investing for the future. Flood and coastal risk management in England. A long-term investment strategy. Environment Agency, Bristol

19. Pitt M. (2008). The Pitt Review. Lessons learned from the 2007 summer floods. Cabinet Office, London

20. House of Commons (2013). Environment, Food and Rural Affairs Committee. Managing Flood Risk. 
Third Report of Session 2013-14. UK Government, London

21. Bourdieu P. (1986). The forms of capital, in Richardson J. eds Handbook of Theory and Research for the Sociology of Education Greenwood, New York 241-258

22. Voinov A. and Bousquet F. (2010). Modelling with stakeholders. Environmental Modelling and Software, 25, 1268-1281

23. Nye M., Tapsell S. and Twigger-Ross C. (2011). New social directions in UK flood risk management: moving towards flood risk citizenship? Journal of Flood Risk Management, 4, 288-297

24. UK Parliament (2010). Flood and Water Management Act 2010, Chapter 29. UK Parliament, London

25. Allen J. and Cochrane A. (2007). Beyond the Territorial Fix: Regional Assemblages, Politics and Power Regional Studies, 41, 1161-1175

26. Meijerink S. and Dicke W. 2008 Shifts in the PublicPrivate Divide in Flood Management. International Journal of Water Resources Development, 24, 499512

27. Cox K. R. (1998). Spaces of dependence, spaces of engagement and the politics of scale, or: looking for local politics. Political Geography, 17 1-23

28. Nicholls W. (2009). Place, networks, space: theorising the geographies of social movements. Transactions of the Institute of British Geographies, 34, 78-93

29. Peck J. and Tickell A. (2012). Apparitions of neoliberalism: revisting 'Jungle law breaks out'. Area, 44, 245-249

30. Defra (2012). Principles for implementing flood and coastal resilience funding partnerships. Environment Agency, Bristol

31. Pearce G. and Ayres S. (2012). Back to the Local? Recalibrating the Regional Tier of Governance in England. Regional and Federal Studies, 22, 1-24

32. Clifford B. P. (2013). Reform on the Frontline: Reflections on Implementing Spatial Planning in England, 2004-2008. Planning Practice and Research, 28, 361-383

33. Allen J. and Cochrane A. (2010). Assemblages of State Power: Topological Shifts in the Organisation of Government and Politics Antipode, 42, 1071-1089

34. Furlong K. (2012). Good water governance without good urban governance? Regulation, service delivery models, and local government. Environment and Planning A, 44, 2721-2241

35. McCarthy J. and Prudham S. (2004). Neoliberal nature and the nature of neoliberalism. Geoforum, 35, 275-283.

36. MacLeod G. and Goodwin M. (1999). Space, scale and state strategy: rethinking urban and regional governance. Progress in Human Geography, 23, 503527 